\title{
FAILURE ANALYSIS OF COMPRESSION HELICAL SPRING USED IN THE SUSPENSION SYSTEM BY FEA
}

MAHER REHAIF KHUDHAIR

AL-Dewaniyah Technical Institute, AL-Furat Al- Awsat Technical University, Iraq

\begin{abstract}
This paper is an investigation and comparison between ASTM A227 and Chromium vanadium AISI 6150 as a material in springs used in vehicles suspension systems. Numerical analysis using ANSYS 16.1 software to calculate the early failure and predict the resistance of the material and under the effect of the harmonic forces of $4250 \mathrm{~N}$ and $4500 \mathrm{~N}$ and the frequency of 100 $\mathrm{Hz}$ at the rate of increase $5 \mathrm{~Hz}$. The results have been shown is concluded, that by using Chromium vanadium AISI 6150 would be highly durable and more efficient for use in suspension systems in the vehicles through riding on the slopes or bumped road. Also, can choose the appropriate material according to loads or weight of the vehicles and operating conditions.
\end{abstract}

KEYWORDS: FEA, Helical Compression Spring, Shear Stress, Deformation \& Frequency Response

Received: Jun 19, 2019; Accepted: Jul 11, 2019; Published: Sep 24, 2019; Paper Id.: IJMPERDOCT201974

\section{INTRODUCTION}

Compression helical springs are important elements in the mechanical design. It's known that the spring function is the absorption of shocks and vibrations, also absorb of energy, therefore, it is necessary to study of the failure of springs, which explained in the shear stress and deformation effects of strength it, under the static or variable loads. In this study, the focus was placed on the resistance of the springs under variable loads (fatigue failure effect). The previous studies have emerged as the following. [1] Studied Max. shear stress and gets percentage error about (1.5\%-4\%) as a compared numerical analysis with theoretical calculations. In addition, interested in ASTM A227 as the material used in vehicles of three-wheels. [2] Reviewed the studies failure of helical springs under the wiggle loading and interested in the calculation of fatigue and max. shear stresses and deflection distribution by FEM programs had been using of performance mesh simulation. In addition, the comparison of the theoretical results with numerical results by FEA, it will conceivable to help designers for the design of springs to prevent failure. [3] Studied distribution of stress, characteristic of materials, manufacture, and failure. Moreover, obtained max. deflection is $(0.313807 \mathrm{~mm}$ in the y-direction), also a high difference in stress between theoretical and FEA (where $1267 \mathrm{MPa}$ in FEA and $1010 \mathrm{MPa}$ in theoretical). In addition, decided the spring failure is possible occurs in the critical section is more than sections compared to others section. [4] Interested in the failure of steel grade 60Si2CrVA as a spring used in heavy-duty vehicles, and focused on a set of recommendations are important to select of non-closed ends for design to avoid of wear, and corrosion of springs. [5] Investigated the failure reduction of springs under the static and dynamic loading, used Pro-E to 3D solid modelling and ANSYS software to analyze and concluded his study to the strength of springs are influenced through the change of coil diameter to maximum expecting to gets the appropriate elastic and inappropriate for the conditions. [6,7] Reviewed to the discussed of mechanical springs design used in the automobiles are perfectly very necessary for designing and analysis which involving stress distribution and maximum extension and different of failure mode. Also, the springs subjected to the oscillating loads through the service, supplement, divers software design such as ANSYS, Solid Works, Pro-E, and 
CATIA, etc., had been used for implementing the stress analysis. Nearly in all cases, fatigue stresses, shear stresses, and max. displacement calculations, played as a role considerable in the mechanical spring design. [8] Focused on two parts of the study (analytical by ANSYS 16 and experimental test), from FEA gets of the fatigue life $\left(6.36\right.$ x $\left.10^{5}\right)$ cycles and max. shear stress is $(715.93 \mathrm{MPa})$ with percentage error $(2.64 \%$ and $2.61 \%$ at max. shear stress), so as for strain gauges in experimental with used five difference of cycles and obtained the genuine of fatigue life are estimated and targeted failures can be evaded, however, improved the aspect safe of the vehicles. [9] Interested in displacement and shear stress and used two materials (chromium-vanadium AISI 6150 and low-carbon steel AISI 1018), used ANSYS R14.5 to analytical with three forces different $(3432.3,4413$, and $4903.3 \mathrm{~N})$, and concluded that by using the Stainless Steel alloy in the springs, the resisting capacity of it will be highest and sufficient for the purpose of domestic. Through the literature studies, indicate that the material used is the basic element that plays a role in mechanical designs.

\section{SELECTION OF MATERIALS}

Generally, steel alloys are used in the suspension system for high resistance to shock, vibration, and variables loading. Therefore is necessary to select the appropriate material for each purpose. This study focused on two different materials (one is ASTM A227 and another is Chromium Vanadium AISI 6150) to investigate the resistance of each material under variable loads conditions. Table (1) shows the chemical composition and the table (2) shows the properties of materials. [10, 11, 12]

Table 1: Chemical Composition

\begin{tabular}{|c|c|c|c|c|c|c|c|c|}
\hline \multirow{2}{*}{ Material } & \multicolumn{7}{|c|}{ Chemical Composition } \\
\cline { 2 - 9 } & Fe \% & Cr \% & Mn \% & C \% & Si \% & V \% & S \% & P \% \\
\hline ASTM A227 & $97.4-99.1$ & ----- & $0.3-1.3$ & $0.45-0.85$ & $0.15-0.35$ & ------ & $0-0.05$ & $0-0.04$ \\
\hline $\begin{array}{c}\text { Chromium Vanadium } \\
\text { AISI 6150 }\end{array}$ & $96.7-97.7$ & $0.8-1.1$ & $0.7-0.9$ & $0.48-0.53$ & $0.2-0.35$ & 0.15 & $0-0.04$ & $0-0.035$ \\
\hline
\end{tabular}

Table 2: Properties of Materials

\begin{tabular}{|c|c|c|c|c|c|c|c|c|}
\hline & \multicolumn{9}{|c|}{ Properties } \\
\cline { 2 - 8 } Material & $\begin{array}{c}\text { Brinell } \\
\text { Hardness }\end{array}$ & $\begin{array}{c}\text { Modulus of } \\
\text { Elasticity } \\
\text { GPa }\end{array}$ & $\begin{array}{c}\text { Fatigue } \\
\text { Strength } \\
\text { MPa }\end{array}$ & $\begin{array}{c}\text { Poisson's } \\
\text { Ratio }\end{array}$ & $\begin{array}{c}\text { Shear } \\
\text { Modulus } \\
\text { GPa }\end{array}$ & $\begin{array}{c}\text { Ultimate } \\
\text { Tensile } \\
\text { Strength } \\
\text { MPa }\end{array}$ & $\begin{array}{c}\text { Yield } \\
\text { Tensile } \\
\text { Strength } \\
\text { MPa }\end{array}$ & $\begin{array}{c}\text { Density } \\
\text { kg/m }\end{array}$ \\
\hline $\begin{array}{c}\text { ASTM } \\
\text { A227 }\end{array}$ & $500-640$ & 198.6 & $900-1160$ & 0.29 & 80.7 & $\begin{array}{c}1720- \\
2220\end{array}$ & $1430-1850$ & 7850 \\
\hline $\begin{array}{c}\text { Chromium } \\
\text { Vanadium } \\
\text { AISI 6150 }\end{array}$ & $200-350$ & 203.4 & $300-750$ & 0.29 & 77.2 & $630-1200$ & $420-1160$ & 7830 \\
\hline
\end{tabular}

\section{COMPRESSION HELICAL SPRING CALCULATION}

Table (3) shows the spring parameters, and figure (1) explained the standard of helical compression spring.[13]

Table 3: Spring Parameters

\begin{tabular}{|l|c|c|}
\hline \multicolumn{1}{|c|}{ Parameters } & Symbol & Units \\
\hline Wire Diameter & $d$ & $\mathrm{~mm}$ \\
\hline Mean Diameter & $D$ & $\mathrm{~mm}$ \\
\hline Outer Diameter & $D_{o}$ & $\mathrm{~mm}$ \\
\hline Spring Index & $C$ & ------- \\
\hline Free Length & $L_{F}$ & $\mathrm{~mm}$ \\
\hline Spring Rate & $k$ & $\mathrm{~N} / \mathrm{mm}$ \\
\hline Pitch & $p$ & $\mathrm{~mm}$ \\
\hline
\end{tabular}




\begin{tabular}{|l|c|c|}
\hline Number of Active Turns & $n$ & ------- \\
\hline Number of Total Turns & $n^{\prime}$ & ------- \\
\hline Deflection & $\delta$ & $m m$ \\
\hline $\begin{array}{l}\text { Modulus of rigidity for } \\
\text { the spring material }\end{array}$ & $G$ & $G P a$ \\
\hline Shear Stress Factor & $K_{S}$ & -------- \\
\hline Wahl's Stress Factor & $K$ & ------- \\
\hline Maximum Shear Stress & $\tau_{\max }$ & $M P a$ \\
\hline Mean Shear Stress & $\tau_{m}$ & $M P a$ \\
\hline Variable Shear Stress & $\tau_{v}$ & $M P a$ \\
\hline Axial Load & $W$ & $N$ \\
\hline Mean Load & $W_{m}$ & $N$ \\
\hline Variable Load & $W_{v}$ & $N$ \\
\hline
\end{tabular}
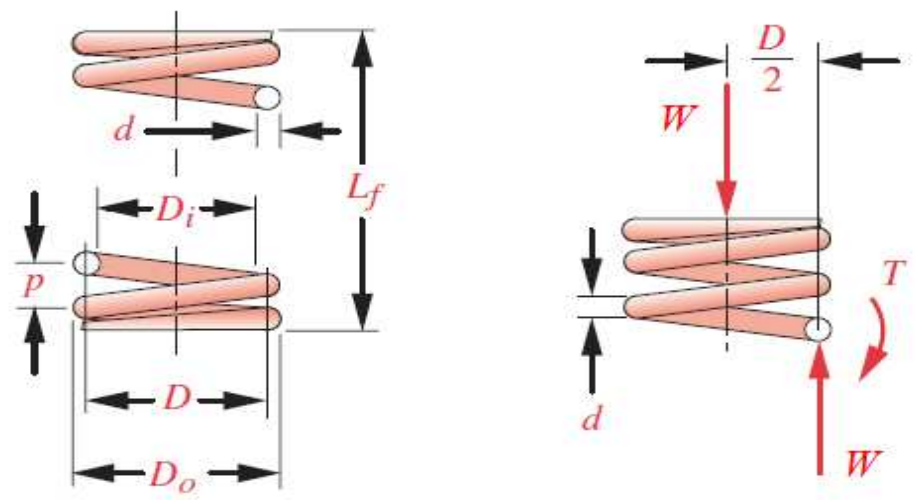

Figure 1: Compression Helical Spring.

\subsection{Maximum Shear Stress}

The helical compression springs are commonly subjected to two types of shear stresses. One is direct shear stress and the other is torsional shear stress. The equations (1-2) represent direct and torsional deflections, while the equation (3) represents the maximum shear stress.

Direct Shear Stress $\tau_{d}=\frac{4 \times W}{\pi \times d^{2}}$

Torsional Shear Stress $\tau_{T}=\frac{8 \times W \times D}{\pi \times d^{3}}$

Max. Shear Stress $\tau_{\max }=\tau_{d}+\tau_{T}$

$$
\left.\begin{array}{l}
\tau_{\text {max }}=\frac{4 \times W}{\pi \times d^{2}}+\frac{8 \times W \times D}{\pi \times d^{3}} \\
\tau_{\max }=K_{S} \times \frac{8 \times W \times D}{\pi \times d^{3}} \\
\tau_{\max }=K \times \frac{8 \times W \times D}{\pi \times d^{3}}
\end{array}\right\}
$$


Where: $K_{S}=1+\left(\frac{1}{2 D}\right)$, and $K=\frac{4 C-1}{4 C-4}+\frac{0.615}{C}$

When the helical springs are subjected to fatigue loading are designed by used the Soderberg line method (1930). The spring materials are commonly examined for endurance torsional strength under repeated stresses that changes from zero to a maximum. The equations $(4 \& 5)$ represents mean shear and variable stresses.

$$
\begin{aligned}
& \tau_{m}=K_{S} \times \frac{8 \times W_{m} \times D}{\pi \times d^{3}} \\
& \tau_{v}=K \times \frac{8 \times W_{v} \times D}{\pi \times d^{3}}
\end{aligned}
$$

Where: $W_{m}=\frac{W_{\max }+W_{\min }}{2}$, and $W_{v}=\frac{W_{\max }-W_{\min }}{2}$

\subsection{Deflection of Compression Helical Spring}

Deflection of helical springs are different according to the carry tensile or compression loading, there are required some means of transferring the loads from the support to the spring body, and the spring is subjects with initial tension. The equation (6) shows of the spring deflection.

$$
\delta=\frac{8 \times W \times C^{3} \times n}{G \times d}
$$

\section{FINITE ELEMENT ANALYSIS}

Table (4) shows the geometry parameters, while the main purpose of using the finite element analysis is to reduce error through the reduction and simplification of equations, especially when it is in the angles of the helical as well as the modelling method. In addition, the accuracy of the results which can be obtained by creating of a three-dimensional geometry of solid model as shown in figure (2) by using the Solid Works 2017 and save it as IGES format file and export it to the ANSYS 16.1 software. Figure (3) represents the three-dimensional geometry of helical compression spring by ANSYS 16.1., while mesh generated as follows (mesh size: proximity and curvature, relevance center: medium, span angle center: medium, and smoothing: medium) as shown in figure (4).

Table 4: Geometry Parameters

\begin{tabular}{|l|c|c|}
\hline \multicolumn{1}{|c|}{ Parameters } & Value & Units \\
\hline Wire Diameter & 13 & $\mathrm{~mm}$ \\
\hline Mean Diameter & 127 & $\mathrm{~mm}$ \\
\hline Outer Diameter & 140 & $\mathrm{~mm}$ \\
\hline Free Length & 425 & $\mathrm{~mm}$ \\
\hline Pitch & 72 & $\mathrm{~mm}$ \\
\hline Number of Active Turns & 7 & ------- \\
\hline Number of Total Turns & 9 & ------- \\
\hline
\end{tabular}




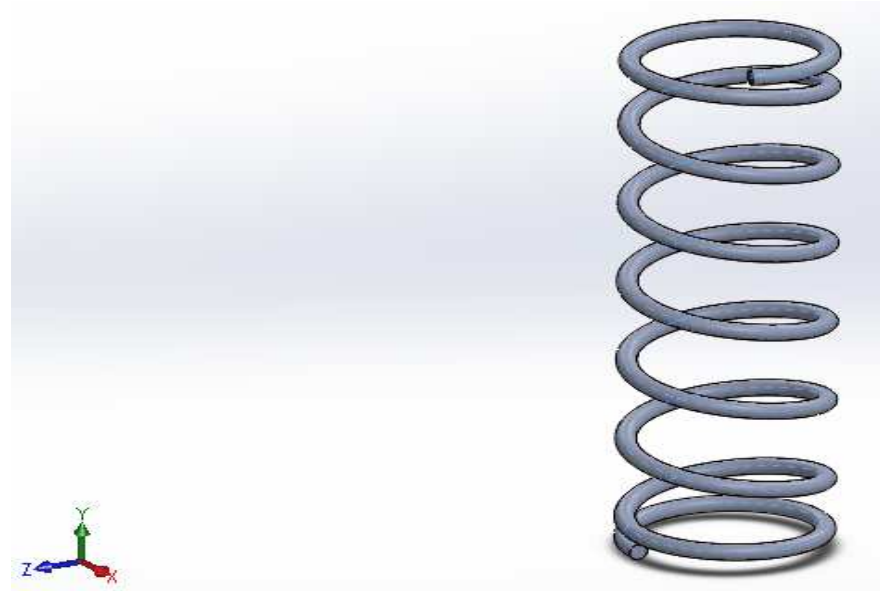

Figure 2: 3D Modelling of Helical Spring by Solid Works.

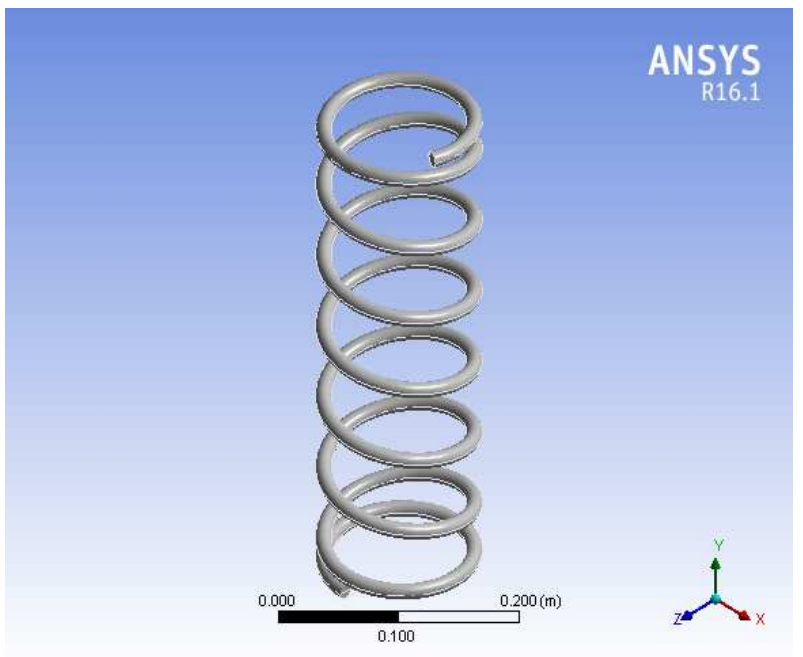

Figure 3: 3D Modelling of Helical Spring in ANSYS.

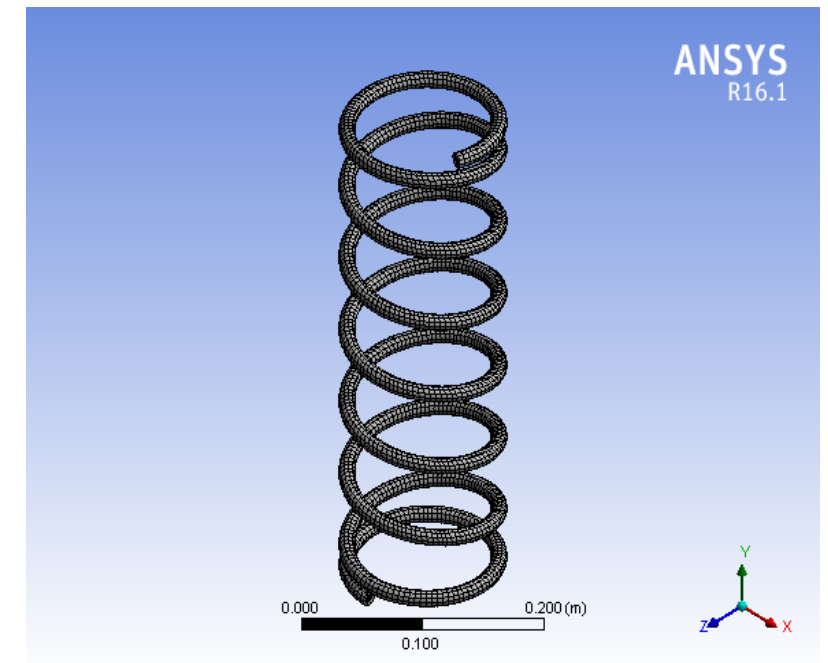

Figure 4: Mesh Generation of Helical Spring.

\section{RESULTS AND DISCUSSIONS}

The materials are examined by used two harmonic forces $(4250-4500 \mathrm{~N})$ as external forces affecting the helical spring. In addition, the harmonic frequency (at the sweeping phase: 0 degrees) as the range of (0 to $100 \mathrm{~Hz}$ ) at an increased rate of $(5 \mathrm{~Hz})$. Through these forces and harmonic frequency, the deformation and shear stress distributions were calculated, and the frequency response of the two examined materials. Through these forces and harmonic frequency, the deformation and shear stress distributions were calculated as the frequency response of the two examined. The figures (5-8) illustrate the distribution of deformation, while the figures (9-12) show the distribution of shear stress. The figures (13-16) show the frequency response. Tables (5-7) explained the comparison of results obtained by numerical analysis of both deformations, shear stress and frequency response, respectively. 


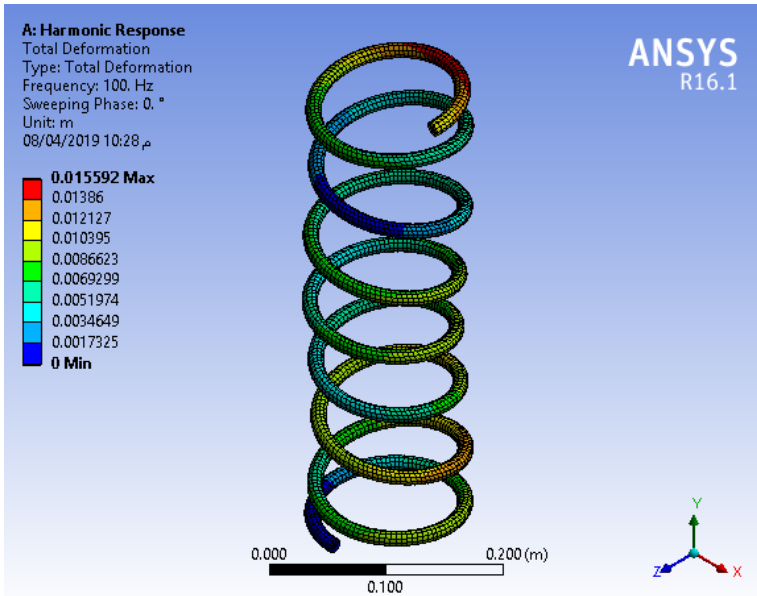

Figure 5: ASTM A227 Deformation at 4250 N.

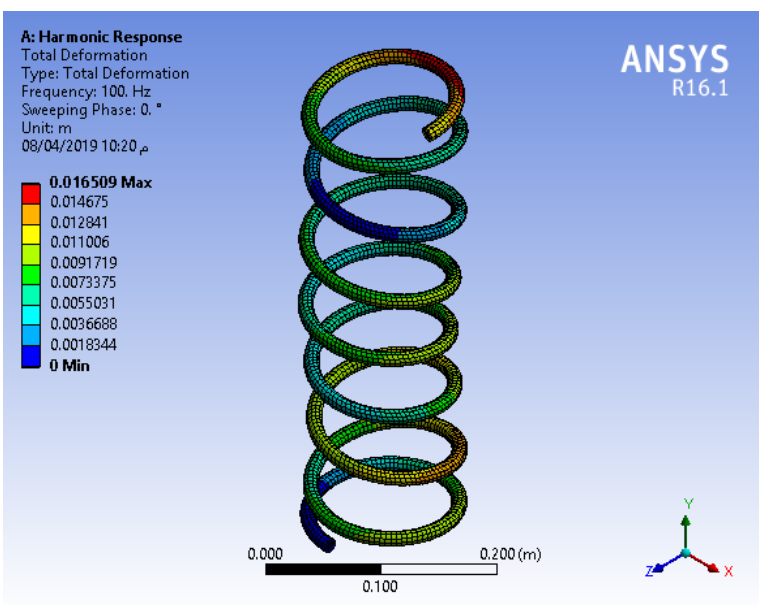

Figure 7: ASTM A227 Deformation at 4500 N.

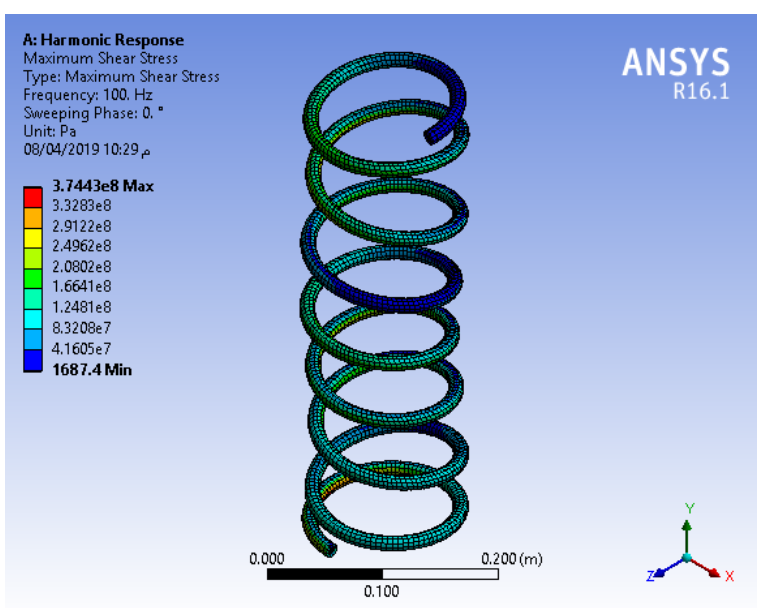

Figure 9: ASTM A227 Shear Stress at 4250 N.

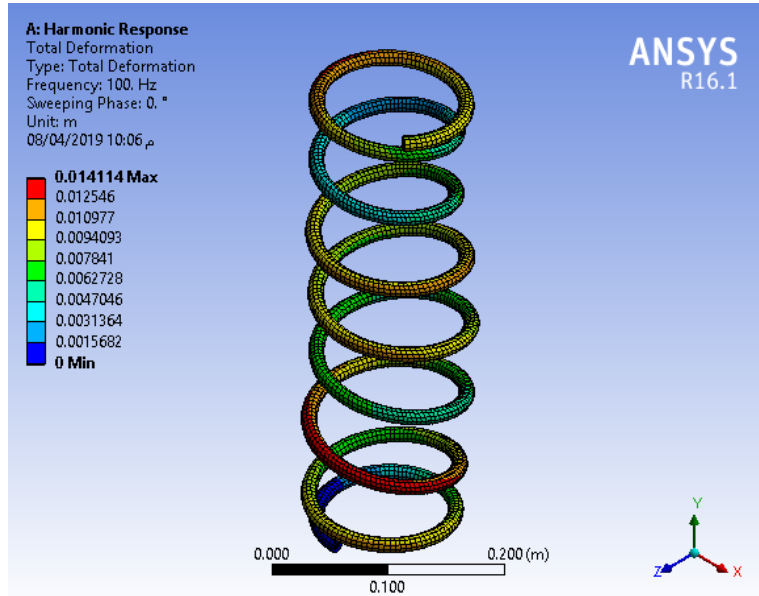

Figure 6: AISI 6150 Deformation at $4250 \mathrm{~N}$.

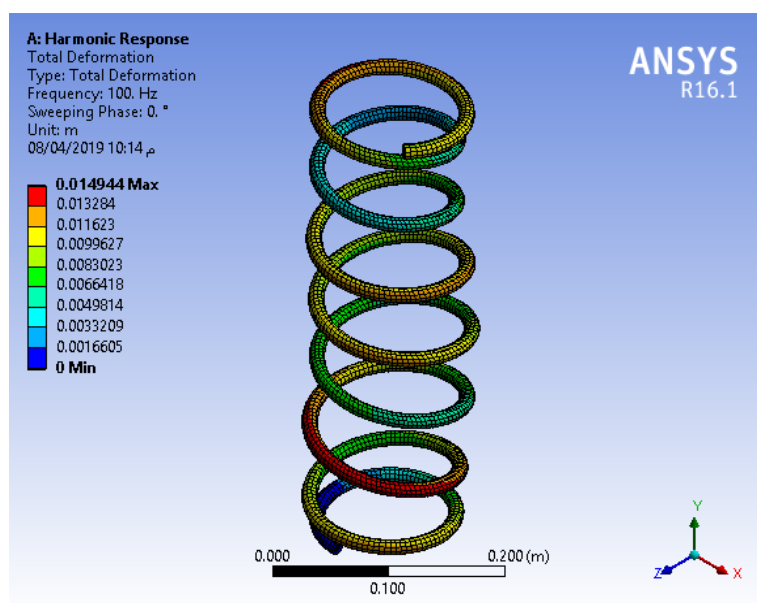

Figure 8: AISI 6150 Deformation at 4500 N.

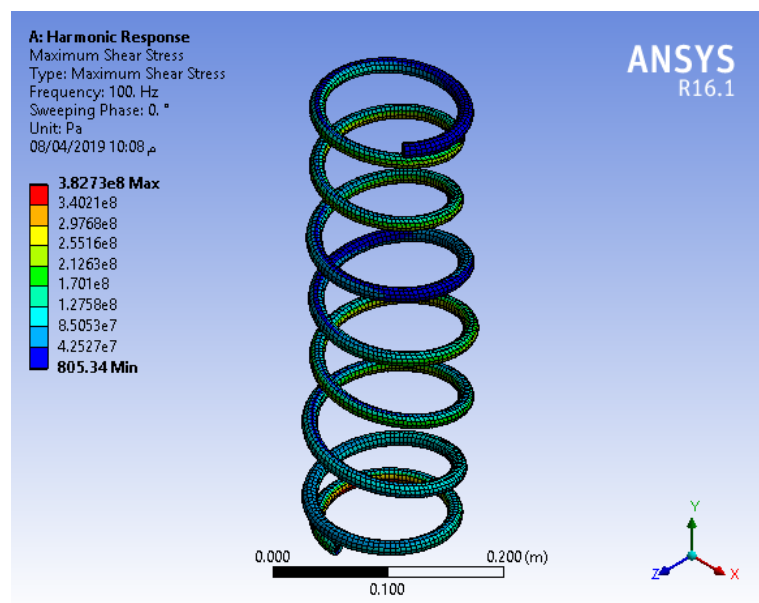

Figure 10: AISI 6150 Shear Stress at 4250 N. 

in the Suspension System by FEA

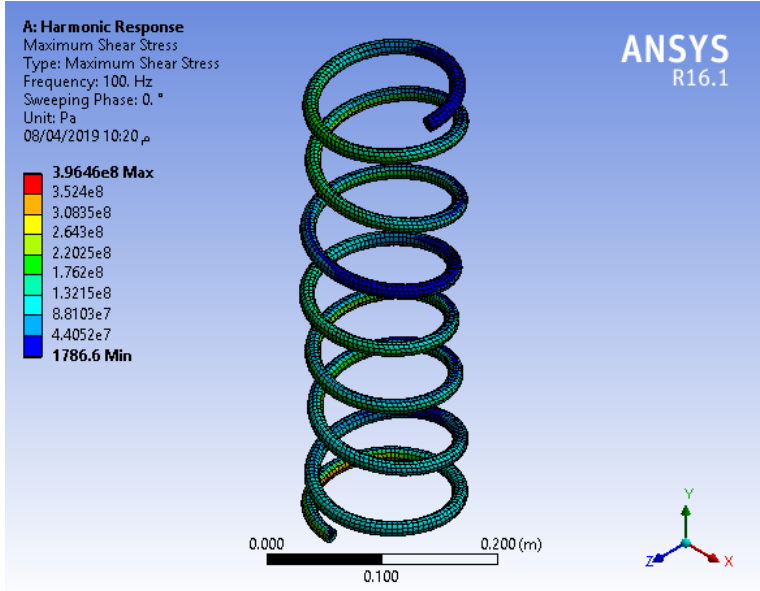

Figure 11: ASTM A227 Shear Stress at 4500 N.

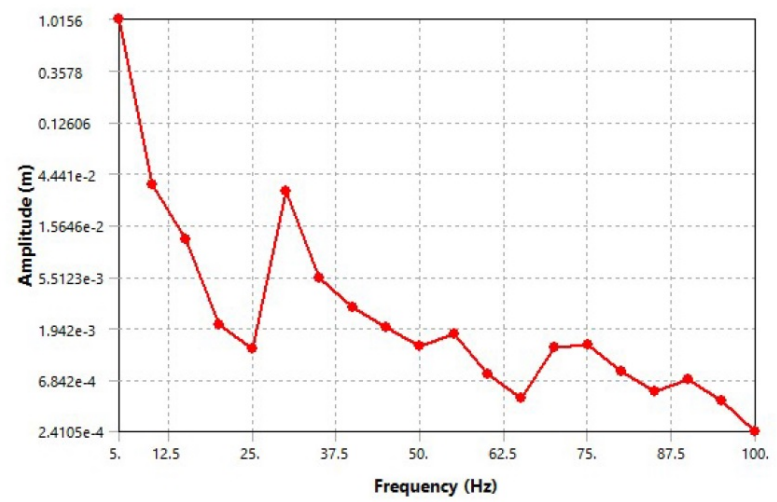

Figure 13: Frequency Rsponse of ASTM A227 at $4250 \mathrm{~N}$.

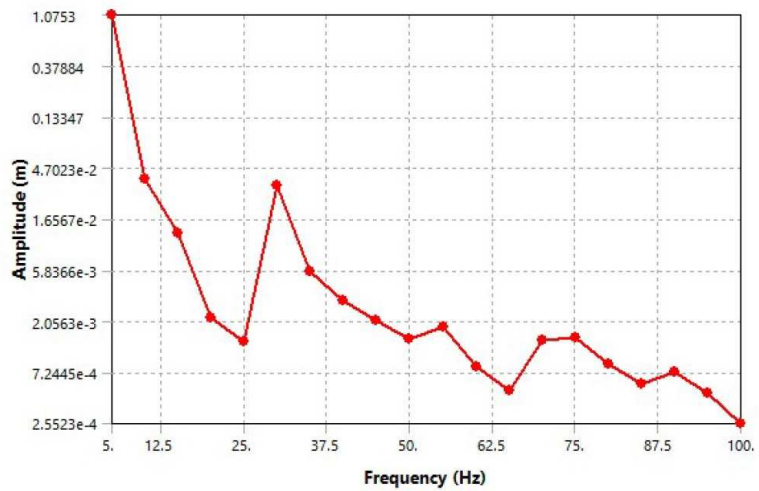

Figure 15: Frequency Response of ASTM A227 at $4500 \mathrm{~N}$.

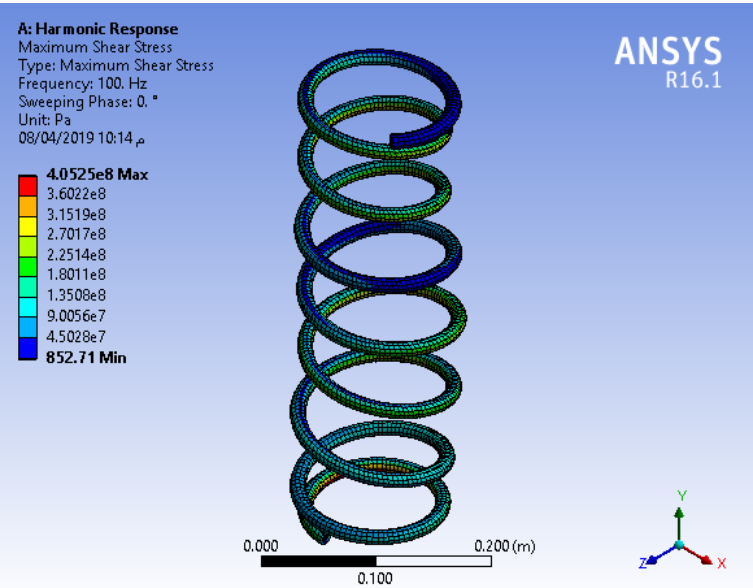

Figure 12: AISI 6150 Shear Stress at 4500 N.

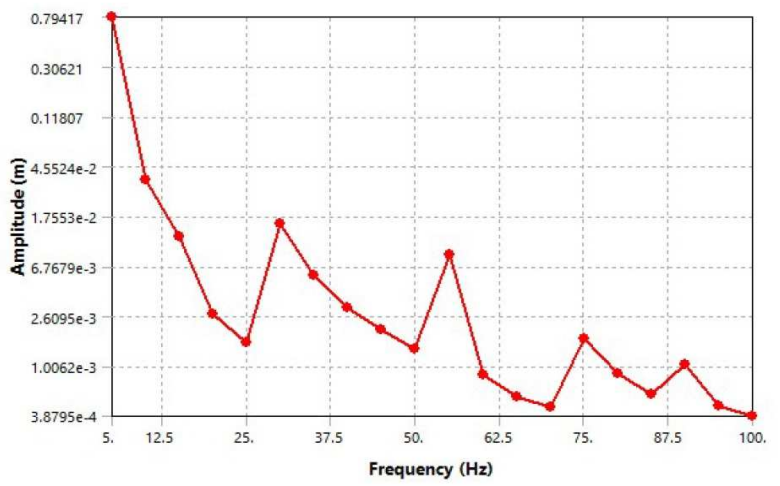

Figure 14: Frequency Response of AISI 6150 at $4250 \mathrm{~N}$.

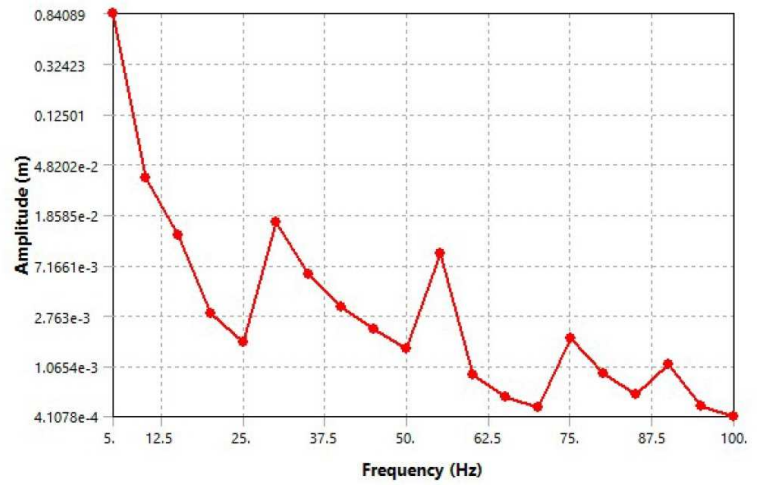

Figure 16: Frequency Response of AISI 6150 at 4500 N.

Table 5: Comparison of Deformation.

\begin{tabular}{|c|c|c|c|}
\hline \multirow{2}{*}{ Force in $\boldsymbol{N}$} & \multicolumn{2}{|c|}{ Maximum Deformation in $\mathbf{m m}$} & \multirow{2}{*}{ Error percentage \% } \\
\cline { 2 - 4 } & ASTM A227 & Chromium vanadium AISI 6150 & 9.4792 \\
\hline 4250 & 15.592 & 14.114 & 9.4796 \\
\hline 4500 & 16.509 & 14.944 & \\
\hline
\end{tabular}


Table 6: Comparison of Shear Stress.

\begin{tabular}{|c|c|c|c|}
\hline \multirow{2}{*}{ Force in $N$} & \multicolumn{2}{|c|}{ Maximum shear stress in MPa } & \multirow{2}{*}{ Error percentage \% } \\
\cline { 2 - 4 } & ASTM A227 & Chromium vanadium AISI 6150 & 2.1686 \\
\hline 4250 & 374.43 & 382.73 & 2.16903 \\
\hline 4500 & 396.46 & 405.25 & \\
\hline
\end{tabular}

Table 7: Comparison of Frequency Response

\begin{tabular}{|c|c|c|c|}
\hline \multirow{2}{*}{ Force in N } & \multicolumn{2}{|c|}{ Maximum amplitude in m } & \multirow{2}{*}{ Error percentage \% } \\
\cline { 2 - 4 } & ASTM A227 & Chromium vanadium AISI 6150 & \\
\hline 4250 & 1.0156 & 0.79417 & 21.802 \\
\hline 4500 & 1.0753 & 0.84089 & 21.79 \\
\hline
\end{tabular}

\section{CONCLUSIONS}

Essentially, in the helical spring, it should resist the load which is subjected to its. However, the suspension system will be safe enough in the wheel. The numerical result of deformation, shear stress, and frequency response are compared between two selected materials. We get that numerical analysis by ANSYS, max. deformation (15.592, 14.114 mm) and max. shear stress $(374.43,382.73 \mathrm{MPa})$ and max. amplitude $(1.0156,0.79417 \mathrm{~m})$ in ASTMA227 and Chromium vanadium AISI 6150 respectively at $(4250 \mathrm{~N})$ as affecting force. In addition, when using (4500 N) as an effective force, we observed increases in deformation $(16.509,14.944 \mathrm{~mm})$ and shear stress $(396.46,405.25 \mathrm{MPa})$ as well as amplitude $(1.0753,0.84089 \mathrm{~m})$ for same materials respectively. Percentage error between ASTM A227 and Chromium vanadium AISI 6150 of deformation is $(9.4792 \%-9.4796 \%)$ and $(2.1686 \%-2.16903 \%)$ for maximum shear stress and $(21.802$ $\%-21.79 \%$ ) for the amplitude.

Finally, we have concluded that by using Chromium vanadium AISI 6150 would be highly durable and more efficient for use in suspension systems in the vehicles through riding on the slopes or bumped road.

\section{REFERENCES}

1. Tausif M. Mulla, Sunil J. Kadam, Vaibhav S. Kengar, Finite Element Analysis of Helical Coil Compression Spring for Three Wheeler Automotive Front Suspension, International Journal of Mechanical and Industrial Engineering (IJMIE), Vol. 2, Issue 3, 2012, p.p. (74-77).

2. Gajendra Singh Rathore, Upendra Kumar Joshi, Fatigue Stress Analysis of Helical Compression Spring: A Review, International Journal of Emerging Trends in Engineering and Development, Issue 3, Vol. 2, May 2013, p. p. (512-520).

3. Manish Dakhore, Bhushan Bissa, Failure Analysis of Locomotive Suspension Coil Spring Using Finite Element Analysis, International Monthly Refereed Journal of Research In Management \& Technology, Vol. II, June 2013, p. p. (96-104).

4. Youli Zhu, Yanli Wang, Yuanlin Huang, Failure analysis of a helical compression spring for a heavy vehicle's suspension system, Case Studies in Engineering Failure Analysis, Vol. 2, August 2014, p. p. (169-173).

5. B. Praveen Kumar, P. Sampath Rao, Investigation on Reduction in Premature Failure of Locomotive Coil Springs, International Journal of Engineering Research \& Technology (IJERT), Vol. 3, Issue 9, September, 2014, p. p. (224-229).

6. Arif Ahmad Ansari, and Prof. K. K. Jain, Review of Design and Numerical Analysis of Helical Spring used in Automobile, Global Journal of Engineering Science And Researches, 3(3), March 2016, p. p. (1-8).

7. Bhambri, P. A. L. L. A. V. I., \& Fleck, B. R. I. A. N. (2016). Drag Reduction using high molecular weight polymers in TaylorCouette Flow. Int. J. Mech. Prod. Eng. Res. Dev, 6, 59-72. 
8. Dhiraj V. Shevale, Niranjan. D. Khaire, Review on Failure Analysis of Helical Compression Spring, International Journal of Science, Engineering and Technology Research (IJSETR), Volume 5, Issue 4, April 2016, p. p. (892-898).

9. Arora, R., \& Dhami, S. S. (2017). Finite Element Analysis and Multibody Dynamics of 6-Dof Industrial Robot.

10. Dhiraj V. Shevale \& Niranjan D. Khaire, Analysis of Helical Compression Spring for Estimation of Fatigue Life, Imperial Journal of Interdisciplinary Research (IJIR), Vol. 2, Issue 10, 2016, p. p. (2088-2093).

11. Ragupathi. P, Dhayanidhi. E, Arunachalam. S, Jegadeshwaran. A, Kamal Hassan. P, Design of Helical Spring Suspension, Imperial Journal of Interdisciplinary Research (IJIR), Vol. 3, Issue 4, 2017, p. p. (1421-1431).

12. Ghosh, S. Rydberg Atom Transition with Quantum Optic Ions with Amplitude Modulation with Response of Pulse Wave.

13. Eugen A. Avallone, Theodore Baumeister III., Standard Handbook for Mechanical Engineers, McGRAW-HILL, Tenth Edition, 1996, p. p. (352-360).

14. Shigley's, Mechanical Engineering Design, McGraw-Hill Primis, Eighth Edition 2006, pp. (506-508).

15. Robert L. Norton, Machine Design: An Integrated Approach, Prentice Hall, Fourth Edition, 2011, p. p. (790-793).

16. R. S. Khurmi, J. K. Gupta, A Textbook of Machine Design, Eurasia publishing house (PVT.) LTD., 2005, p. p. (825-854).

17. Fegade, V., Ragavendran, U., \& Ramachandran, M. Numerical Investigation of Hybrid Helical Spring for Total Deformation and Von Mises Analysis. 
